Efficacy of laser preionisation with a semiconductor source and propene addition

This article has been downloaded from IOPscience. Please scroll down to see the full text article.

1984 J. Phys. E: Sci. Instrum. 171242

(http://iopscience.iop.org/0022-3735/17/12/036)

View the table of contents for this issue, or go to the journal homepage for more

Download details:

IP Address: 130.159.17.137

The article was downloaded on 10/05/2010 at 14:28

Please note that terms and conditions apply. 


\section{Efficacy of laser preionisation with a semiconductor source and propene addition}

\author{
S J Scott $\dagger$ and A L S Smith $\ddagger$ \\ $\uparrow$ British Aerospace Dynamics Group, Sowerby Research \\ Centre, P O Box 5, Filton, Bristol BS 12 7QW, UK \\ \$ Physics Department University of Strathclyde, John \\ Anderson Building, 107 Rottenrow Glasgow G4 ONG, UK
}

\section{Received 18 July 1984}

Abstract. It is established that propene is an effective additive in stabilising uv preionised $\mathrm{CO}_{2}$ TEA laser discharges: its effect being particularly pronounced with semiconductor-edge preionised lasers where the preionisation levels are shown to be low.

There is sustained interest in compact TEA $\mathrm{CO}_{2}$ lasers yielding the maximum laser peak power from the minimum excited volume ( $\left.>100 \mathrm{MW}^{-1}\right)$; this requires a judicious combination of high specific energy input $\left(>200 \mathrm{~J} \mathrm{~J}^{-1}\right)$ and high $\mathrm{CO}_{2}$ content (up to 50\%) in the mixture (Smith et al 1984). To avoid discharge arcing such devices need not only well controlled electric fields (profiled electrodes and control of pulse risetime etc) and suitable gas mixtures, but also effective preionisation. In this note we comment briefly on two recent developments in preionisation technique: the use of the low ionisation potential additive propene and the use of semiconductor-edge preionisers.

The semiconductor-edge preioniser was introduced by Rickwood (1982); it involves an almost continuous filamentary discharge between the edges of a semiconductor and a conductor (which may be one of the main electrodes) or another semiconductor along the length of the main discharge. Advantages claimed over discrete spark preionisers include the ability to site the preioniser close to the main discharge without cross-arcing, less sputtering from the preioniser, less $\mathrm{CO}_{2}$ dissociation in the filamentary discharge than in an array of discrete arcs and improved energy outputs (Rickwood 1982, Pace et al 1983, Stark and Crocker 1984). To measure the production of photoelectrons by a semiconductor source we have adapted our photoionisation chamber (Scott and Smith 1982), with the discrete spark source being replaced by a $2 \mathrm{~mm}$ thick 200 ohm-cm rectangular silicon plate $(7 \mathrm{~mm} \times 14 \mathrm{~mm})$ with one $7 \mathrm{~mm}$ edge adjacent to $(<1 \mathrm{~mm})$ a stainless steel electrode. A pulsed high voltage is applied between the metal electrode and the far end of the semiconductor and the electron production measured at a distance of $100 \mathrm{~mm}$. With a typical laser mixture and source excitation we would expect to measure $10^{7}$ to $10^{8}$ electrons $\mathrm{cm}^{-3}$ from a single spark source; with the semiconductor we were unable to observe a signal (detection limit $10^{6}$ electrons $\mathrm{cm}^{-3}$ ). With various adjustments (changing the gas mixture to reduce the $\mathrm{CO}_{2}$ absorption and increasing the sensitivity by modifying the electrometer time constant etc) we eventually obtained a signal of $2 \times 10^{5} \mathrm{~cm}^{-3}$ in a $\mathrm{CO}_{2}$ free mixture (whereas an equivalent signal spark gave $1.6 \times 10^{8}$ ). We were then able to estimate the photoelectron production as $10^{6}$ electrons $\mathrm{cm}^{-3}$ at a distance of 10 to $20 \mathrm{~mm}$ from a semiconductor source in a typical laser with a typical laser mixture. This is two orders of magnitude less than a single spark will produce and suggests that the uniformity of the preionisation is important, and in semiconductor preionised systems the good uniformity partly at least compensates for the reduced level of preionisation.

With a $10 \% \mathrm{CO}_{2}, 20 \% \mathrm{~N}_{2}, 70 \% \mathrm{He}$ mixture in a prototype and non-optimised semiconductor preionised laser (discharge $20 \mathrm{~mm} \times 20 \mathrm{~mm} \times 500 \mathrm{~mm} 50 \mathrm{ohm}-\mathrm{cm}$ silicon slabs along each side adjacent to the anode) the maximum energy input boundary before arcing was $100 \mathrm{~J} \mathrm{I}^{-1}$ and the output $2.5 \mathrm{~J}$ at $12 \%$ efficiency. Upon addition of 100 PPM propene the output was not increased for the same input, but the loading could be increased to $340 \mathrm{~J}^{-1}$ before arcing (the output for $200 \mathrm{~J}^{-1}$ was $4.5 \mathrm{~J}$ at $11 \%$ efficiency). Apparently the semiconductoredge preionisation in this device was inadequate and it could benefit considerably from the extra electron yield with the propene addition: but this improvement is because of access to a regime of higher specific energy input, not because of improved energy utilisation.

To examine further the tentative conclusion that the major effect of the propene addition is to enhance the preionisation electron density we used a miniature TEA spark-uv preionised laser, known to be excellently preionised without additives (Smith et al 1984). This laser has a $7 \mathrm{~mm} \times 8 \mathrm{~mm} \times 104 \mathrm{~mm}$ discharge volume and was operated with a $15 \%$ transmitting $\mathrm{ZnSe}$ output coupler and a $33 \% \mathrm{CO}_{2}, 33 \% \mathrm{~N}_{2}, 34 \% \mathrm{He}$ gas mixture. Arc free operation was obtained with a $6 \mathrm{nF}$ supply capacitor over the range 18 to $30 \mathrm{kV}$ and the output energy was 50 to $85 \mathrm{~mJ}$ (see figure 1) and the peak power 0.5 to $1 \mathrm{MW}$ : the addition of propene ( 5 to $125 \mathrm{PPM}$ ) did not change the energy, peak power or pulse shape. With a $9 \mathrm{nF}$ capacitor supply voltages over $24 \mathrm{kV}\left(450 \mathrm{~J} \mathrm{I}^{-1}\right)$ resulted in some pulses arcing and the average pulse energy rapidly decreased at higher voltages: however the addition of 400 PPM propene allowed access to a region of higher specific energy input $\left(450-600 \mathrm{~J} \mathrm{I}^{-1}\right)$ with relatively arc free operation. Note that at the lower voltages the energy output is decreased: this was attributed to absorption of the laser radiation (alkenes have a strong absorption between $10 \mu \mathrm{m}$ and $11 \mu \mathrm{m}$ ). Smaller amounts of the propene (40 and 100 PPM) did not reduce the energy at the lower voltages, but the improvement at the higher voltages was even less pronounced. We also noted that when the laser was sealed-off arcing started after $\sim 1000$ shots (presumably due to $\mathrm{O}_{2}$ build-up and accidental trace additive removal (Scott and Smith 1984)), but propene addition delayed this until 2000 to 3000 shots.

We conclude that propene is especially useful as a low ionisation potential additive because it can be easily added as it

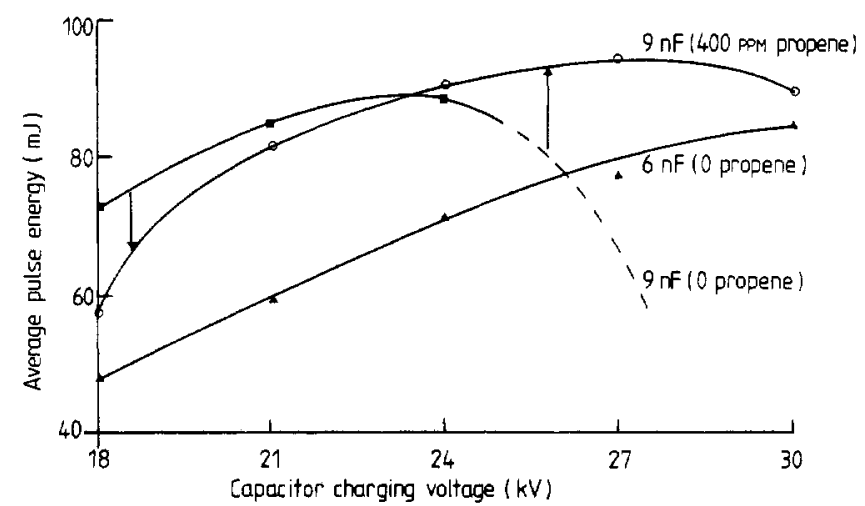

Figure 1. Variation of laser pulse energy (each point averaged over 10 shots) with supply capacitor charging voltage, showing the effects of propene addition. 
is a gas - indeed it can be incorporated in premixed gas cylinders. Its utility is in delaying the onset of arcing and allowing access to regimes which would otherwise be unstable. These advantages may be considerable in an otherwise poorly preionised system, but are marginal in already well preionised systems. Semiconductor-edge preionisation appears to lead to low intensity, but uniform, gas preionisation and hence is one of those systems which may benefit from propene addition.

\section{Acknowledgments}

Work on the semiconductor preionised laser was carried out at British Aerospace, the rest was undertaken at Strathclyde University under the sponsorship of SERC and Barr and Stroud. We acknowledge with thanks the assistance of Drs P Dickinson and $\mathrm{R}$ Winfield and $\mathrm{Mr} \mathrm{N}$ Campbell.

\section{References}

Pace P, Hale $M$ and Cruickshank J 1983 A simplified, miniature TEA $\mathrm{CO}_{2}$ laser using a semiconductive pre-ionisation technique Opt. and Laser Technol. 15 189-90

Rickwood K R 1982 A semiconductor preioniser for TEA $\mathrm{CO}_{2}$ lasers

J. Appl. Phys. 53 2840-2

Scott S J and Smith A L S 1982 Sources of photoionisation in transversely excited atmospheric $\mathrm{CO}_{2}$ lasers

Appl. Phys. Lett. 41 783-5

Scott S J and Smith A L S 1984 Identification of the origins of photoionisation in $\mathrm{CO}_{2}$ TEA lasers

Appl. Phys. B 33 1-5

Smith A L S, Sephton J P and Scott G 1984 High-peak power extended lifetime sealed TEA $\mathrm{CO}_{2}$ lasers J. Phys. E: Sci. Instrum. 17 590-8

Stark D S and Crocker A 1984 A sealed high PRF semiconductor-preionised TEA laser without a solid catalyst . Opt. Commun. $48337-42$ 